UNIO - EU Law Journal. Vol. 4, No. 2, July 2018, pp 33-41.

®2018 Centre of Studies in European Union Law

School of Law - University of Minho

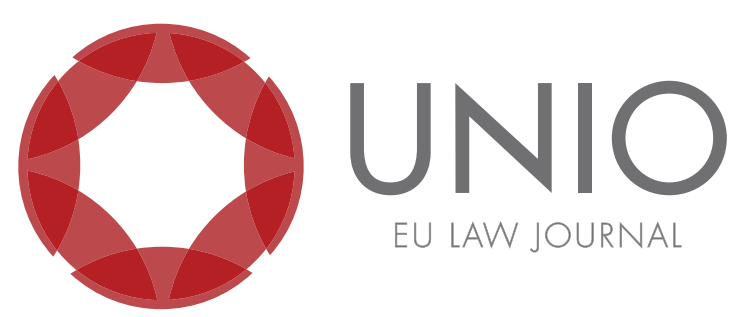

\title{
Social and political challenges of the Digital Single Market and of increasing connectivity: digital literacy and network power
}

\section{Elsa Costa e Silva*}

ABSTRACT: This article seeks to reflect on the construction of a Digital Single Market (DSM) and on initiatives aimed at increasing the connectivity of European citizens. The widespread access to internet has obvious advantages for citizens and businesses, but it also gives rise to challenges for society. There are two principal issues. Firstly, digital literacy and the power of the players. First, the benefits of the availability of a particular technology do not just result from widespread access. They result, to a large extent, from the capacity of people to take advantage of the use and from the practices that are promoted. Thus, policies to promote technology cannot be dissociated from policies to promote media and digital literacy. Secondly, generalizing access to the Internet can further enhance the power of the players who, at this moment, already concentrate a large part of Internet users' activity. This issue concerns matters of economic competition, but also of social power to provide symbolic frameworks to read the world.

KEYWORDS: Digital Single Market - connectivity - digital literacy - power - democracy.

\footnotetext{
* Professor at the Department of Communication Sciences of the Social Sciences Institute of the University of Minho. Researcher at the Communication and Society Research Center.
} 


\section{Introduction}

The generalization of free and easy Internet access in all European public spaces, a concept that supports the Wifi4EU initiative, is a step towards a scenario of a connected Europe, where $21^{\text {st }}$ century citizens can be permanently online without obstacles. This objective, which was set in the midst of the Information or Knowledge Society, seeks to ensure that citizens acquire certain competences in terms of the use of technologies, thus promoting the consolidation of a knowledge-based competitive economy at a macro level. It is one of the measures that could contribute to the consolidation of a DSM, where all people and companies can reach digital opportunities. In the context of difficult access to the labor market, where the consequences of the sharp economic crisis are still felt, the capacity to acquire and apply new knowledge and skills related to the use of digital media has been increasingly valued in today's society. ${ }^{1}$

At the individual level, and considering the weight that the internet has in the lives of people due to the penetration of social networks and the use of a large number of services (such as online shopping and the relationship with public administration), this initiative can prove itself an advantage for the convenience of the citizen. In addition to being connected, able to relate to a vast network of friends and other contacts, it is on the Internet that the citizen consumes news (a growing practice, given the decrease of paper circulation) and entertainment content. There are also opportunities to integrate online political processes and debates, increasing the ability to participate in civic actions and other citizenship practices. Therefore, facilitating access in the public space, where people are moving, away from home or work and traditional access, can have a significant impact, especially considering the increasing importance of mobile devices. For those who do not have a fixed broadband connection, it may be the opportunity to access and connect.

The generalization of Internet access may, thus, have obvious advantages, but it also challenges society. The aim of this article is to systematize, in two main rationales, a brief reflection on some of these challenges, offered by the enlargement of the connectivity to European citizens: digital literacy and power of the actors. First, the benefits of the availability of a particular technology do not just result from widespread access. The results depend on, to a large extent, the capacity of people to take advantage of this use. Thus, technology promotion policies cannot be dissociated from policies to promote media literacy and digital literacy. Secondly, generalizing access to the Internet can further enhance the power of the actors who, at the moment, already concentrate a large part of Internet users' activity. Without intervention in this field, traditional business models and services, of which journalism media are currently one of the main victims, will continue to be at stake.

\section{Access and literacy}

Since 2000 and the Lisbon Strategy, the European Union has established guidelines for shaping all the social systems of Member States to a society and economy based on information and knowledge. In this context, enabling the citizens of the Member States to use digital technologies is an objective that could impact on the economic and social fabric, promoting the development of the Information Society.

The European Digital Agenda, which has been developed, has recently been

\footnotetext{
${ }^{1}$ Bernie Trilling and Charles Fadel, 21st Century Skills: Learning for Life in Our Times (San Francisco: John Wliley \& Sons, 2009).
} 
leveraged with the Wifi4EU initiative, which envisages a budget of 120 million euros between 2017 and 2019 to promote free Wi-Fi in public spaces. The initiative is foreseen in Regulation (EU) 2017/1953 of the European Parliament and of the Council of 25 October 2017, which states that "improving access to high-speed and very-high-speed broadband and consequently to online services, especially in rural areas and remote locations, could increase quality of life by facilitating access to services, for example e-Health and e-Government, and could promote the development of local small and medium-sized enterprises".

However, considerations about the straightforward relationship between connectivity and direct benefits in terms of quality of life should be viewed with caution. The scientific evidence on the use of the internet illustrates the existence of a digital divide that creates restrictions on access (in terms of the competences required, which affects the less literate and socially disadvantaged classes). In other words, the problem is not so much access (or a lack thereof) to a computer and the internet, but it is set in the field of cultural and strategic competences that allow the use of technology to reap the benefits, socially, civically, and politically. ${ }^{2}$ Thus, connectivity does not automatically guarantee access to information made available online, since this implies organization, detection and reading skills that are not equally distributed among the population.

This raises the issue of media literacy, that is, "the ability to access, analyze, evaluate and create messages in different ways" ${ }^{3}$, in a dynamic learning process in which the different components are interconnected. Access is a first step, but it is not enough to ensure that the information available is analyzed either, to ensure that the sources of that information are valid or to discern its reliability, which is essential in this age of 'information abundance" and fake news. According to Cardoso, "citizenship in a network society also depends on the mastering of the instruments that allow us to deal with the media as a natural language". 5

These considerations have to be read within a framework of critical reflection on technology and on more utopian perspectives on its potential benefits. Also, this issue should not be considered only in the more economic perspective of the DSM. The European Commission has shown that it is aware of the importance of digital literacy, noting that "in today's world, citizens need to develop analytical skills that allow for better intellectual and emotional understanding of digital media". 6

This means that measures of generalized access and increased connectivity should be accompanied by digital literacy programs. The European Commission itself has issued a recommendation to the Member States to adopt a perspective of action to promote media literacy. According to the same text, "a media literate society would be at the same time a stimulus and a precondition for pluralism and independence in the media" and that "the expression of diverse opinions and ideas, in different languages, representing different groups, in and across societies has a positive impact on the values of diversity, tolerance, transparency, equity and dialogue". ${ }^{7}$

\footnotetext{
${ }^{2}$ Nico Carpentier, Media and Participation (Bristol: Intellect, 2006).

${ }^{3}$ Sonia Livingstone, Media literacy and the challenge of new information and communication technologies (London: LSE Research Online, 2004), 5.

${ }^{4}$ Sonia Livingstone, Media literacy..., 7.

${ }^{5}$ Gustavo Cardoso, Os media na sociedade em rede (Lisboa: Fundação Calouste Gulbenkian, 2006).

${ }^{6}$ European Commission, Recommendation on media literacy in the digital environment for a more competitive audiovisual and content industry and an inclusive knowledge society, C(2009) 6464 final.

${ }^{7}$ Ibidem
} 


\section{a. Literacy and democracy}

The position of the European Commission puts this reflection in a domain that is equally essential when it comes to connectivity and access to the internet: its civic potential and the exercise of citizenship. To date, the Internet has been used more for entertainment than for political participation. However, the potentialities of connectivity in this domain should neither be ignored nor overvalued. For example, the multiplication of information and of communication platforms has resulted in the so-called "communicative abundance" where pluralism and diversity - central political values in a democracy - would be ensured without the need for any other intervention or regulation. ${ }^{9}$ However, although there is space for all to participate and for all voices and social perspectives to be represented in the new digital public space, the greater diversity and availability of new voices and sources of information on the Internet does not mean that they are listened to or even acknowledged. ${ }^{10}$

On the other hand, more channels in numerical terms do not necessarily mean that they are channels with really different provisions. ${ }^{11}$ This is a concern that the European Parliament shares, stating in a 2008 report on media concentration and pluralism in the Union (2007/2253 (INI)) that "new technologies, and in particular the shift to digital technology for the production and dissemination of audiovisual content and the entry on the market of new communications and information services have significantly influenced the quantity of available products and means of dissemination; whereas, however, a quantitative increase in media and services does not automatically guarantee content diversity".

The second level of analysis in this era of "supersaturation"12 or "cultural chaos"13 stems from the fact that the virtues of pluralism can only be promoted if there are connection points and mutual recognition, in which differences can be confronted and accommodated. ${ }^{14}$ It is not enough that opinions find a space in these new platforms, because although there is no shortage of space, there is a limited ability to pay attention. In addition, there are also issues of media literacy skills that limit widespread use and harnesses the potential of new technologies by the population. That is, it is not enough that there is diversity and pluralism in the platforms, it is also necessary that the citizens are actually exposed to this content. ${ }^{15}$

Increasing connectivity, as the Wifi4EU initiative expects, and doing so separately from digital literacy, may mean increasing some of the problems that have already been identified in the digital space. One of them has exactly to do with the above discussion, the one of the lack of exposure to diverse content. The algorithms

\footnotetext{
${ }^{8}$ John Keane, Public life and late capitalism: toward a socialist theory of democracy (Cambridge: Cambridge University Press, 1984).

${ }^{9}$ Tim Gardam, "The purpose of plurality", in The price of Plurality, ed. T. Gardam and D. A. L. Levy, (Oxford: Reuters Institute, 2008).

${ }^{10}$ Hannu Nieminen and Josef Trappel, "Media serving democracy”, in Media in Europe Today, ed. J. Trappel, W. A. Meier et al. (Bristol: Intellect Books, 2010).

${ }^{11}$ Michael M. Epstein, "From scarcity to market power Quid Pro Quo: toward a workable right of access in U.S. Media”, in Media Ownership - research and regulation, ed. R. E. Rice (Cresskil: Hampton Press, 2008).

${ }^{12}$ Todd Gitlin, Media Unlimited: How the Torrent of Images and Sounds Overwhelms Our Lives (New York: Henry Holt, 2002).

${ }^{13}$ Brian McNair, Cultural Chaos - Journalism, News and Power in a Globalised World (London: Routledge, 2006).

${ }^{14}$ Tim Gardam, The purpose of plurality...

${ }^{15}$ Kari Karppinen, "Rethinking media pluralism and communicative abundance", Observatorio (OBS*) Journal 11 (2009): 151-169.
} 
used by social networks to select the content that is made available to users' feeds privilege their tastes and preferences. This means that users tend to only consume and share news, information, videos with which they already agree with and identify with. They are thus not confronted with difference, opposition, and debate that are essential in democratic societies, creating the effect of 'cyberbalcanization" 'bomophilia. ${ }^{17}$ If people gather in networks where the same type of thinking reigns, then the internal interaction will result in a greater homogenization of that group and in a greater cleavage in the face of opposing thoughts. The explanation for this lies in factors such as the reinforcement of opinion, by means of the majority positions, and the need for the individual to be perceived by others in a favorable way. If increased connectivity increases political and social cleavages, the positive effects of the Wifi4EU initiative can be diluted in the face of renewed social and political tensions.

\section{b. Internet and surveillance}

More literacy is also needed to help users recognize commercial practices and forms of protection against undue or abusive forms of electronic surveillance. In fact, one of the problems raised in cyberspace is the surveillance that is carried out on users. ${ }^{18}$ This surveillance has mainly economic objectives, aiming at the definition of profiles of consumers to whom personalized advertising can be targeted. But it may also have a component of political vigilance and state security, as the recent Snowden scandal has revealed.

The concept of privacy is currently much disputed, with companies, states and users having diverse views on the subject ${ }^{19}$. More critical perspectives point out to the ambiguity of its conception in capitalist societies where companies see their privacy protected while violations of consumer and citizen privacy are legitimized ${ }^{20}$, with social networks such as Facebook monitoring their users' online activities (such as contacts, communications, and data) to sell this information to advertisers.

Dean argues that internet economic players promote the existence of entertainment networks that involve users in flows and circuits that distract them and absorb them, so as to extract data essential for the sale of products, but also to remove them from genuine and committed political activity. ${ }^{21}$ The illusion of participation, provided by initiatives such as signing online petitions or commenting on politicians' Facebook pages, discourages more concrete political intervention initiatives such as participation in street protests or partisan mobilizations.

In this current context of connection and connectivity, privacy is increasingly not perceived as a right of users, but as a commodity that can be traded in exchange

\footnotetext{
${ }^{16}$ Mark Tremayne, "Harnessing the active audiences: Synthesizing blog research and lessons for the future of media", in Blogging, citizenship, and the future of media, ed. M. Tremayne (New York: Routledge, 2007).

${ }^{17}$ Cass R. Sunstein, "Neither Hayek nor Habermas", Public Choice 134 (2008): 87-95.

${ }^{18}$ Christian Fuchs, "The contemporary world wide web: social medium or new space of accumulation", in The Political Economies of Media - The transformation of the global media industries, ed. D. Winseck and D. Y. Jin (London: Bloomsbury, 2012); Christian Fuchs, Social Media: a Critical introduction (London: Sage, 2013). ${ }^{19}$ Katherine Sarikakis and Lisa Winter, "Social Media Users' Legal Consciousness About Privacy", Social Media + Society 3(1) (2017).

${ }^{20}$ Christian Fuchs, "The political economy of privacy on Facebook", Television \& New Media 13(2) (2012): 139-159.

${ }^{21}$ Jodi Dean, Blog theory: Feedback and capture in the circuits of drive (Cambridge/Malden: Polity Press, 2010).
} 
for benefits such as human connection and digital access to friends; it is also exchanged for state security. ${ }^{22}$ The complexity of the concept has grown, with wide divergences among users themselves, who have very different notions about what privacy is. States and business actors also have divergent considerations about the complexity of the concept, which makes the discussion on electronic surveillance a contested domain.

Thus, connectivity cannot be considered disconnected from issues of exposure to difference, privacy and surveillance - issues that directly call on citizens' literacy skills. However, while a critical understanding of literacy points out a multidimensional concept ${ }^{23}$, documents and discourses tend to focus on a more functional and instrumental approach to the use of digital technologies, namely its potential contribution to economic development. ${ }^{24}$ Thus, any policy of generalization of connectivity should actively consider literacy strategies that emphasize the diverse competences that this concept encompasses: understanding, reflecting, criticizing, selecting, and evaluating the information and communication process, as well as producing and participating.

\section{Access and equity among the players in the digital market}

In addition to the issues related to the promotion of digital literacy, that is, with the perspective of the reception of the services and contents provided by the Internet, the promotion of a DSM cannot also forget the offer-side of services and content, that is, it cannot ignore its structure and organization and the challenges that arise from it. Most Internet users focus on a few platforms, including e-mail services, search engines (such as Google), and social networks (such as Facebook, Instagram, or Twitter), which poses questions of concentration of network power.

This means a large number of users concentrate their online time and attention on practices and activities carried out on a few platforms, which thus, have significant power in this space. This power is so significant that it has been difficult and time consuming for the States, or for the European Union, to impose rules in fiscal or even legal terms - as the case on Google demonstrates. Therefore, in addition to the well-known architectural features of the Internet itself that prevent attempts of traditional regulation or governance, there is also the power of large companies, such as Google and Facebook, to which the States have had difficulty in regulating.

\section{a. Governing the Internet?}

Internet governance is a current topic that is far from reaching consensus or universal solutions. According to Silva, "bistorically we have witnessed a great reluctance to regulate the virtual world, a type of Internet-phobia retrieved from the best doctrine, the network ab initio being characterized by a space of anarchy, insubmissible to the sovereignty of an autonomous government or of any centralized body capable of imposing behaviors". ${ }^{25} \mathrm{~A}$

\footnotetext{
${ }^{22}$ Katherine Sarikakis and Lisa Winter, Social Media Users'...

${ }^{23}$ Leena Rantala and Juha Suoranta, "Digital Literacy Policies in the EU - Inclusive Partnership as the Final Stage of Governmentality?”, in Digital Literacies: Concepts, policies and practices, ed. Colin Lankshea and Michele Knobel (New York, Peter Lang, 2008), 91-118.

${ }^{24}$ Sara Pereira, "More technology, better childhoods? The case of the Portuguese 'One Laptop per Child' programme”, Communication Management Quarterly 29 (2013), 171-198.

25 Hugo Lança Silva, "O direito no mundo dos blogues", https://www.verbojuridico.net/doutrina/ tecnologia/blogues.html, April 2005.
} 
promising tool in terms of the expression of fundamental freedoms and of the promotion of citizenship and democracy, the Internet can also present itself as a space where offensive content, child pornography, terrorism and economic crime proliferate. Efforts to find a global governance for the Internet, notably at the level of the United Nations, dating back to the mid-1990s and involving a number of international agencies, are thus justified but have yet to progress significantly.

The lack of centralized regulation on the Internet is explained by the circumstances of its development through an open and free access computing infrastructure. ${ }^{26}$ One of the major obstacles would be the lack of agreement on basic principles and rules of Internet operation ${ }^{27}$, from which one could think about the framework of regulation. The Internet does not have an effective authoritative system for enacting rules and enforcing them. ${ }^{28} \mathrm{~A}$ technological basis difficult to control and its global reach, which gives rise to jurisdictional conflicts, are the main difficulties that this idea of regulation presents. The United Nations have approved the Tunis Declaration, which reaffirms the governance of the Internet as a central theme of the agenda, advocating for a multi-stakeholder model. This institution currently supports a working group, the Internet Governance Forum, a space for reflection and proposals on this subject, which promotes annual meetings with partners, interest groups and states, in order to promote regulatory initiatives.

Internet governance has been promoted through the involvement of various stakeholder groups in multilateral processes, a mechanism that has been used throughout history to coordinate management of shared spaces and/or resources. This collaborative exercise, referred to as "multistakeholderism", indicates decisionmaking processes that involve a wide consultation of all stakeholders. However, this model has received very little critical attention, and has not been sufficiently examined in relation to the promises of its suitability for the development of the internet. ${ }^{29}$ For example, Raymond and DeNardis argue that this process often fails to live up to its multi-party rhetoric and that "across a number of crucial governance functions, the reality is perhaps closer to industry self-regulation than to genuine multistakeholder governance". ${ }^{30}$ Madeline Carr argues that this process serves, in large part, to reinforce existing power relations (that is, those of the US government and those aligned with a US agenda), and that civil society remains relatively disempowered, even though it performs an important role of legitimacy for other stakeholders; summing up, "the private sector is dominated by US multinationals (...), and governments show no significant signs of relinquishing their conventional hold on sovereign power".

\footnotetext{
${ }^{26}$ Manuel Castells, A Era da Informação: Economia, Sociedade e Cultura (Vol.I) - A Sociedade em Rede (Lisbon: Fundação Calouste Gulbenkian, 2005).

${ }^{27}$ Milton Mueller et al., "The Internet and Global Governance: Principles and Norms for a New Regime”, Global Governance 13 (2007): 237-254.

${ }^{28}$ Hans Klein, "ICANN and Internet Governance: levering technical coordination to realize global public policy", The Information Society 18 (2002): 193-207.

${ }^{29}$ See Madeline Carr, "Power plays in global internet governance", Millenium - Journal of International Studies 43(2) (2015): 640-659; Daniel W. Drezner, "The global governance of the Internet: bringing the state back in”, Political Science Quarterly 119(3) (2004): 477-498; Claudia Padovani and Elena Pavan, "Diversity reconsidered in a global multi-stakeholder environment: insights from the online world", in The Power of Ideas: Internet Governance in a Global Multistakeholder Environment, ed. Wolfgang Kleinwächter (Berlin: Germany Land of Ideas, 2007), 99-109.

${ }^{30}$ Mark Raymond and Laura DeNardis, "Multistakeholderism: anatomy of an inchoate global institution", International Theory 7(3) (2015), 603.
} 
A traditional position of the European Commission has been to address Internet governance issues through the lens of the competition policy, but now there is a growing awareness that new Internet issues, such as digitalization and data analysis, for example, offer new challenges. Thus, the EU has been pressured on the need to adopt a broader regulatory perspective, integrating consumer policy and data protection policy into its action. ${ }^{31}$ A new data protection framework, arising from the publication of the General Data Protection Regulation [Regulation (EU) 2016/679], will come into force in May 2018, but more fundamental measures are needed to allow the EU to impose itself as an inevitable actor in this process and oppose the major interests of US corporations.

Although some technical aspects are involved, most of the process is political in nature. Even technical infrastructure issues have strong policy implications. It is the case of Internet protocol management, which controls the global flow of information and influences access to knowledge and has clear consequences for online civil freedoms, privacy, national competitiveness and the digital economy. ${ }^{32}$ On the other hand, the Internet has not been immune to the logic of privatization and to the domination of global corporations ${ }^{33}$, in particular by internet service providers and telecommunications companies, which raises old issues of access and control in the new digital age.

\section{b. Internet and national media economies}

This dominance of the major global players should also be seen as a challenge when considering the generalization of access, because more people accessing a mean strengthening the power of these same players, to the detriment of European and national players. Looking particularly at the case of the national media and journalistic industries, whose role in democracies is undeniable, this problem has been acute, especially with regard to journalistic companies that have seen their traditional business model, based on advertising and circulation revenues, failing.

The economic success of Facebook and Google platforms, as advertising and marketing companies, results from attracting a large number of users. As a consequence of this organization, what characterizes the commercial patterns of the Internet is not decentralization, democratization or cooperation, but concentration, control and power. ${ }^{34}$ The major problem with this situation is that these platforms are not merely services, but social contexts, where social relations and readings of the world are played and from an economic point of view, national media, which are also central due to the symbolic frameworks they provide to their societies, do not have the capacity to compete.

The change in the consumption of news, to which the digitalization of the economy significantly contributed, imposed the "free" culture. The practice of consulting and consuming information for free has hindered the transition from paid paper circulation to paid online consumption models. On the other hand, the news

\footnotetext{
${ }^{31}$ Wolfgang Kerber, "Digital markets, data, and privacy: competition law, consumer law and data protection”, Journal of Intellectual Property Law \& Practice 11(11) (2016): 856-866.

${ }^{32}$ Laura DeNardis, Protocol Politics - the globalization of Internet Governance (Massachussets: MIT, 2009).

${ }^{33}$ See Madeline Carr, Power plays in global...; Laura DeNardis, Protocol Politics...; Milton Mueller et al., The Internet and Global Governance...

${ }^{34}$ Ulrich Dolata, "Apple, Amazon, Google, Facebook, Microsoft: Market concentration-competitioninnovation strategies”, Stuttgarter Beiträge zur Organisations-und Innovationsforschung, SOI Discussion Paper (No. 2017-01).
} 
media now suffer from competition for advertising revenues from social networks and search engines that have significant advantages in the identification of potential consumers (by profiling, as noted above).

Two essential problems for national journalistic companies add up to this transition in advertising industry. First, in addition to competing with large platforms for advertising revenues, news media are also deprived of the possibility of monetizing their online presence, since the practice of aggregating content by search engines and of sharing information on social networks removes traffic from their sites. This means that these companies are supplying a large part of the information that feed these networks, but they do not benefit from it. They have the costs associated with the production of the news information, but do not receive the due counterparts for its consumption. On the other hand, the de-territorialization of these activities disturbs the traditional fiscal architecture, which makes the national companies compete at an unequal level in terms of taxation. For example, despite capturing a very significant share of the advertising spending in Portugal, neither Google nor Facebook pay taxes in Portugal.

Therefore, increasing connectivity for the European citizens without considering the impacts that this measure will have on the power of economic players means increasing the gap between the already powerful Internet players and the national and European companies that are depleting.

\section{Final considerations}

The DSM is a challenge for European society and is not without social and political risks, as this paper has sought to demonstrate. The consideration of measures to increase connectivity, taking into account only possible economic advantages, draws from the equation equally important dimensions, in cultural and civic terms, which must not be forgotten. The path of technology cannot be separated from the path of literacy or from the reflection on the potential impacts of technology.

Privacy, surveillance, exposure to differences and reinforcement of network power are some of the themes that should accompany the implementation of technological measures, as it is the case with Wifi4EU. Challenges have been identified and their inclusion in the DSM equation will be essential for an economically developed Europe, but equally mindful from a social and political point-of-view. 